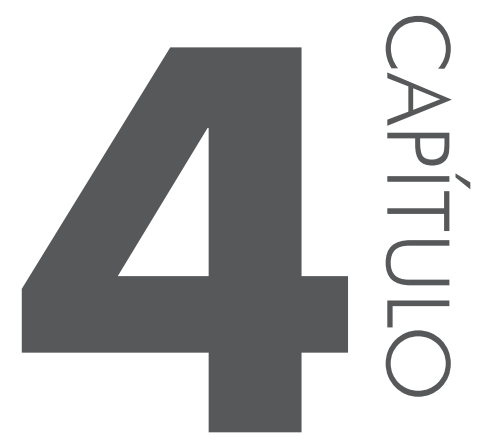

\title{
O observatório da transumância
}

\section{Samuel Rodrigues Aço}

Centro de Estudos do Deserto - CE.DO

Njambasana - Kuroka, abril de 2012

Com este projeto, pretende-se criar um Observatório da Transumância na região sudoeste de Angola, que engloba as províncias da Huíla, Namibe e Kunene. Um dos principais objetivos deste projeto, numa área de alta vulnerabilidade climática à qual está associada uma intensa transumância associada à criação de gado, é identificar esses movimentos, caracterizá-los nas suas causas e consequências, contribuindo para a disponibilização de dados pertinentes para o desenvolvimento e melhoria das condições de vida das populações locais. A pesquisa é simultaneamente qualitativa e quantitativa, apostando fortemente na disseminação dos seus resultados junto de atores chave e demais partes implicadas nas dinâmicas do desenvolvimento do sudoeste de Angola.

A transumância é um fenômeno global (fato social total), transversal, que ocorre em todo o sudoeste de Angola durante certas épocas do ano e faz movimentar pessoas e gado em número avultado e não conhecido. Apesar de existirem vários estudos sobre o gado e o fenômeno da transumância nessa região, nomeadamente o realizado por Castanheira Diniz em 1989, tratam-se de estudos eminentemente técnicos, visando a fixação e concentração do gado, com pouca incidência sobre a componente humana. Desconhece-se igualmente se foram realizadas experiências para a estabulação do gado e fixação da população e os resultados obtidos. As intervenções realizadas nestes últimos anos ficam muito aquém das preconizadas no estudo referido. E o que sucede às pessoas e aos grupos domésticos a que pertencem, envolvidos na criação e pastorícia do gado 
na região, tem sido absolutamente ignorado, tanto pelas autoridades como pela sociedade em geral.

$\mathrm{Na}$ verdade, as populações potencialmente compreendidas nesse fenômeno, sobre o qual se pretende fazer uma observação e recolha científicas, deslocam-se e entrecruzam-se em territórios que antes estavam marcadamente identificados como espaços de uma única comunidade étnica. Contudo, atualmente certas áreas constituem uma amálgama de populações e culturas, não deixando, no entanto, de se sentir a predominância de uma comunidade que lhe confere a identidade e mantém as suas estruturas próprias através das instituições do poder tradicional.

Verifica-se desse modo que, apesar de a transumância percorrer circuitos de há muito estabelecidos e aceitos pelas comunidades, existem cada vez mais circulações que dizem respeito às atividades comerciais e ainda outras, que são recomposições daquelas produzidas pelos efeitos da guerra. Para além desses aspectos, há outros de grande importância, como, por exemplo, um tipo de movimentação cíclica observada, ocasionada pelas secas que de tempos em tempos assolam algumas áreas da região, forçando à deslocação de pessoas e gado para outros locais, mais favoráveis à sobrevivência. Crê-se existir uma regularidade estatística entre os períodos de seca, de grande seca e de chuvas, que os geógrafos podem determinar, e que evidentemente será importante conhecer, de modo a avaliar as consequências sociais dessas deslocações massivas de população e descrever a forma como obtêm hospitalidade e guarida junto dos habitantes de outras regiões, também eles carentes e quase sempre nos limites da disponibilidade de recursos.

Esse conjunto de dados resultantes de uma observação mais empírica, e, por isso, menos científica e sistêmica, leva a considerar que a criação de um Observatório da Transumância pode assegurar o acesso à recolha de dados e ao seu tratamento com uma garantia científica, produzindo-se conclusões inovadoras e sustentadas.

As questões de partida a serem trabalhadas no contexto do observatório podem ser identificadas, de uma forma sintética, do seguinte modo:

- Que tipo de regularidades ou padrões de mobilidade e comportamentos associados a esta se encontram na região?

- Quais as causas dessa mobilidade e os fatores mais relevantes em termos de riscos econômicos, sociais, ambientais?

- Que consequências é possível identificar, nomeadamente em termos das estruturas do poder tradicional; das relações sociais, econômicas e culturais entre as populações transumantes e as comunidades de acolhimento; da relação e implicações do endêmico fenômeno do roubo de gado na transumância; da transformação das identidades e sentimentos de pertença, tendo em conta também a presença de outros atores, como as autoridades administrativas locais? 
Obtido esse retrato, a análise centrar-se-á na transumância como, por um lado, uma necessidade e prática de matriz cultural e, por outro, como objeto de transformação por força das intervenções relacionadas com o crescimento econômico e com o desenvolvimento local que um pouco por toda a parte vão se sucedendo. Torna-se, portanto, importante registar o que acontece e o que vai acontecendo na vida social, econômica e cultural dessas comunidades, como se processam as mudanças e o sentido que tomam.

Face ao enunciado, a criação de um observatório de registro e análise da transumância possibilitará a disponibilização de dados importantes a um conjunto de atores relevantes, nomeadamente às próprias populações locais (transumantes e sedentárias), às instâncias da governação local e nacional e a outros atores interessados, como sejam os investidores. A um nível mais abrangente, e por se tratar sobretudo de uma investigação de caráter científico, permitirá o registro dessas realidades e das transformações em curso, constituindo-se como memória e compreensão do fenômeno e das comunidades nele envolvidas.

\section{Caracterização do espaço geofísico e do contexto social, económico e culfural}

Para este projeto, considera-se o sudoeste de Angola como uma extensa região distribuída por três províncias e dez municípios, estendendo-se por uma área aproximada de 100 mil km². Esses dez municípios compreendem ainda comunas, bairros e setores, os quais são também administrados localmente por autoridades tradicionais.

Tabela 4.1 - Distribuição administrativa das províncias do sudoeste de Angola

\begin{tabular}{|c|c|c|}
\hline PROVÍNCIA & MUNICÍPIOS & COMUNAS \\
\hline \multirow{3}{*}{ NAMIBE } & Bibala & Bibala \\
& Caitou \\
& Virei & Kapangombe \\
& Lola \\
\cline { 2 - 3 } & \multirow{2}{*}{ Tombwa } & Virei \\
\cline { 2 - 3 } & & Kahinde \\
\cline { 2 - 3 } & & Tombwa \\
& & Yona \\
& & Baía dos Tigres \\
\hline
\end{tabular}




\begin{tabular}{|c|c|c|}
\hline \multirow[t]{2}{*}{ HUÍLA } & Chibia & $\begin{array}{c}\text { Chibia } \\
\text { Kapunda-Kavilongo } \\
\text { Kihita } \\
\text { Jau }\end{array}$ \\
\hline & Gambos & $\begin{array}{l}\text { Chianje } \\
\text { Tchimbemba }\end{array}$ \\
\hline \multirow{6}{*}{ KUNENE } & Kahama & $\begin{array}{l}\text { Kahama } \\
\text { Otchinjau }\end{array}$ \\
\hline & Ombadja & $\begin{array}{c}\text { Xangongo } \\
\text { Ombala yo Munge } \\
\text { Humbi } \\
\text { Mucope } \\
\text { Naulila }\end{array}$ \\
\hline & Cuanhama & $\begin{array}{c}\text { Ondjiva } \\
\text { Nehone-Kafima } \\
\text { Evale } \\
\text { Mongua } \\
\text { Simporyonde } \\
\text { Tchiporo }\end{array}$ \\
\hline & Namakunde & $\begin{array}{c}\text { Namakunde } \\
\text { Melunga (Chiede) }\end{array}$ \\
\hline & Kuroka & $\begin{array}{l}\text { Onkokua } \\
\text { Chitado }\end{array}$ \\
\hline & Kuvelai & $\begin{array}{c}\text { Kuvelai } \\
\text { Kalonga } \\
\text { Kubati (Tchissuati) } \\
\text { Mupa }\end{array}$ \\
\hline
\end{tabular}


Apesar da grande extensão e diversidade climática da região, sobressai o fato da escassez e irregularidade no acesso à água, exceto no município da Chibia, podendo considerar-se como uma região árida, com zonas que chegam a atingir a aridez extrema e até o deserto. Torna-se, por isso, mister avaliar as condições de obtenção e uso da água pelas populações que habitam essa região. A água, recurso precioso e raro, assume-se como fator primordial na forma como as sociedades organizam o seu ciclo produtivo, o tipo de interação que estabelecem com o meio ambiente e entre si e com as comunidades vizinhas. Buscamos responder aos constrangimentos causados pela escassez crônica da água e à ocorrência cíclica de grandes secas. As necessidades humanas da água ultrapassam largamente a quantidade que biologicamente o ser humano está obrigado a consumir diariamente e refletem os seus hábitos, usos e costumes, os valores culturais e o tipo de economia subjacente a cada sociedade.

Tabela 4.2 - Estimativa dos rebanhos nas províncias de Huíla, Cunene e Namibe

\begin{tabular}{|c|c|c|}
\hline PROVÍNCIA & BOVINOS & CAPRINOS/OVINOS \\
\hline Huíla & 1.300 .000 & 510.000 \\
\hline Kunene & 900.000 & 120.000 \\
\hline Namibe & 330.000 & 70.000 \\
\hline TOTAL & 2.530 .000 & 700.000 \\
\hline
\end{tabular}

Nesse caso, em que a escassez da água é nota dominante, toda a organização econômica e social, a ocupação e uso do solo e as relações de produção que se estabelecem baseiam-se principalmente na criação de gado, nomeadamente bovino, caprino e ovino, por não existirem condições para a prática de uma agricultura que, por si só, garanta a sobrevivência das famílias.

$\mathrm{Na}$ ausência do censo populacional em nível nacional, usualmente utiliza-se a informação sobre o número aproximado de habitantes, existente nas administrações municipais, que é, de qualquer modo, um dado relevante. As informações disponíveis indicam, para essa área, densidades populacionais que vão dos 5 aos 8 habitantes $/ \mathrm{km}^{2}$, exceto nos municípios Virei, Bibala e Tombwa, onde os valores nunca ultrapassam 1 habitante $/ \mathrm{km}^{2}$. Em relação ao gado, a distribuição aproximada por províncias indica uma elevada concentração nas províncias Huíla e Kunene. 


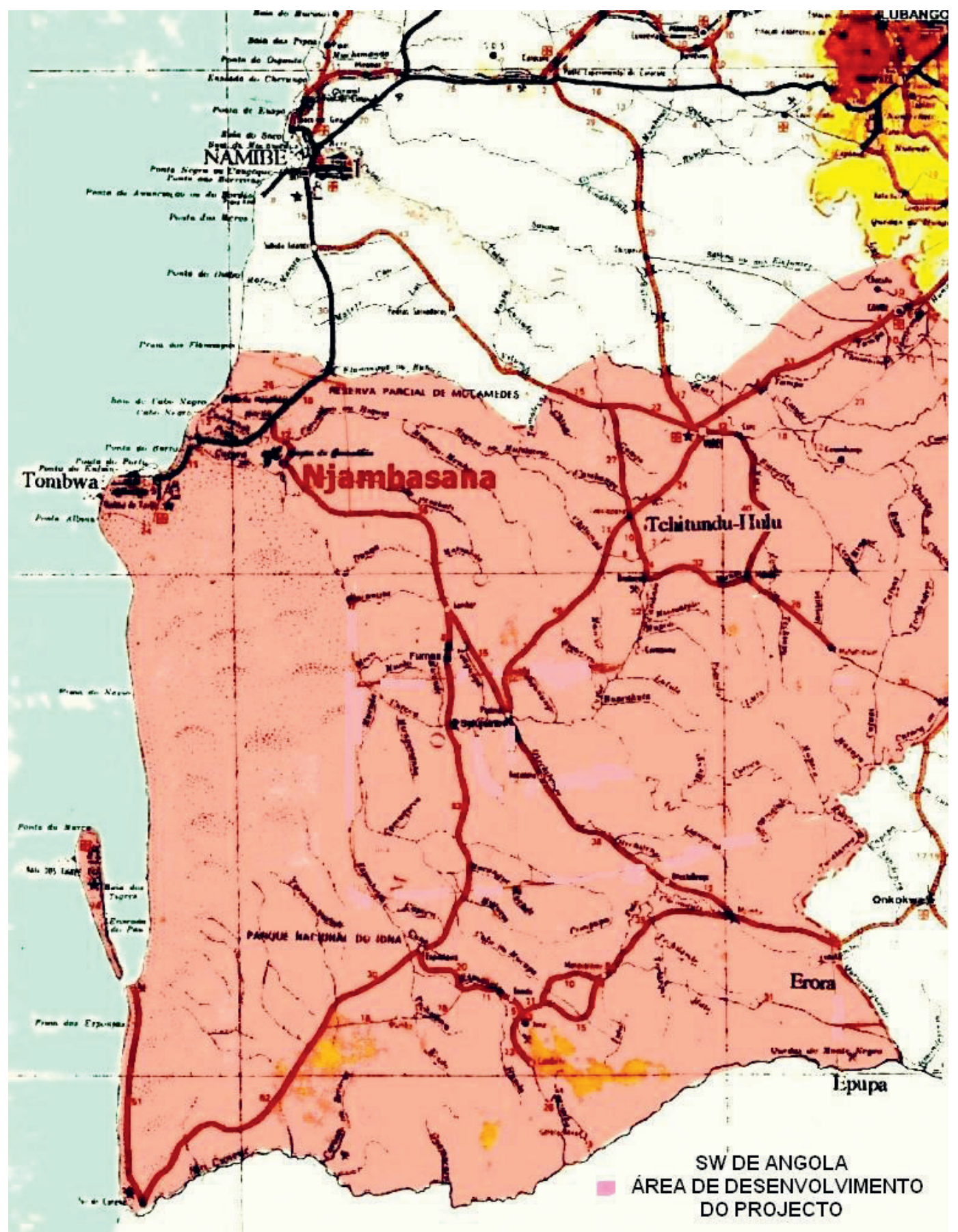

Figura 4.1 - Área de abrangência do Observatório da Transumância. Fonte: CE.DO 
Todas as comunidades de criadores-pastores de gado estabelecem uma relação com os animais, que ultrapassa os fatores de valoração econômica, para constituírem um complexo sistema de relações, que dá conteúdo ao próprio sistema social. Os rebanhos são muito importantes em toda a região, e a sua gestão exige um conhecimento generalizado do espaço e das quantidades de pasto e de água disponíveis em cada momento do ano.

Assim, regiões mais áridas como as planícies no sopé das montanhas do Yona, que se cobrem de erva na época da chuva, apresentam alguma água disponível nessa altura e, sendo escassamente povoadas, recebem nessa ocasião o gado, principalmente bovino, vindo de Erora, 100 quilômetros a leste. A transumância é uma regra geral. Normalmente só o gado bovino, principalmente aquele que não é destinado ao leite doméstico, é que se desloca. Por vezes, é forçoso fazer deslocar os rebanhos de todas as espécies. Para isso, é necessário conhecer o estado das pastagens e da água no local do destino. Para essa tarefa, são encarregados principalmente os jovens ainda não aptos para casar (mutjihita), mas também mulheres e homens adultos.

$\mathrm{Na}$ época das movimentações transumantes, há uma grande circulação de pessoas e gado na região, sobretudo a prospectar as condições existentes para o gado no destino previsto. É muito importante para essas populações o conhecimento do espaço disponível para a prática da transumância. As deslocações que se repetem de ano para ano (se bem que por vezes se passe um ou mais anos sem que um determinado local seja visitado) obedecem a um conhecimento muito concreto e sedimentado no tempo, dos locais, quantidade e qualidade dos pastos e água e número de animais, próprios e de outros pastores, que o espaço suporta e que para ali se irão deslocar.

Acontece, muitas vezes, tornar-se necessário dividir as manadas e rebanhos de forma a racionalizar o uso das pastagens, pois apenas um destino não é suficiente para receber todo o gado de uma onganda (casa principal). Para isso, cada grupo doméstico possui, em diferentes áreas do território, uma ou mais residências temporárias (ohambo/sambo) para onde se deslocam durante a transumância. Embora o uso do território esteja aberto a quem dele necessitar, a regulação desse uso é feita pelos chefes locais (sobas). Por vezes, é interditada a circulação de animais vindos de certas regiões, como forma de evitar a propagação de doenças. Por outro, é tida em conta a capacidade de sustentação de animais que os espaços possuem, para que não suceda o sobrepovoamento e consequente desgaste e desequilíbrio ecológico.

No entanto, dadas as características climáticas da região em que a incerteza é a norma, por vezes as expectativas são frustradas, e acabam por se concentrar demasiadas cabeças de gado num espaço que perdeu a capacidade de as sustentar. Os pastores têm soluções de recurso, que utilizam nessas situações, como, por 
exemplo, colher e secar as folhas do mutiati, que assim podem servir de alimento para as cabras. É frequente também os bovinos se alimentarem das coriáceas e ásperas folhas da welwitschia mirabillis, deixando apenas o núcleo central que possui a consistência de uma rocha, mas tem a capacidade de se regenerar e produzir novas folhas. Como último recurso e alterando rotas antigas e preestabelecidas, buscam os locais onde a água permanece por mais tempo e onde é possível encontrar uma flora ribeirinha de valor inestimável nessas ocasiões.

Existem várias lagoas permanentes nesse território, constituindo verdadeiros oásis onde se pode encontrar vegetação durante todo o ano (em anos de chuva), mas aí podem suceder conflitos com agricultores que utilizam o mesmo espaço. $\mathrm{Na}$ verdade, o único local onde há a certeza de existência de água e vegetação permanentes em qualquer época do ano, mesmo nos anos de seca, são as margens do rio Kunene. Por isso, como refere o Chefe Mutidi Mbendura, "ali é o celeiro de todos, mesmo dos mais pobres, onde sempre podem encontrar comida para pessoas e animais".

As perdas de animais são por isso muito grandes em certas épocas e em certos anos, quando o ciclo de chuva e seca atinge o ponto mais baixo de pluviosidade, com vários anos de ausência total de quedas. A necessidade de conjugar a existência de pastos com a de água a uma distância praticável nem sempre é possível. O gado bovino não se pode deslocar para mais de seis quilômetros dos pontos de água e, à medida que esses vão desaparecendo ao longo da estação seca, torna-se necessário transumá-lo para locais com água mais acessível que, por infortúnio, podem já não ter capim. Por isso, é frequente encontrar extensões apreciáveis de herbáceas sem qualquer animal nos arredores e também (com menos frequência), locais com água, abandonados.

São múltiplos os constrangimentos a que estão sujeitos os criadores de gado da região. Existem diferenças de comportamento entre o gado bovino e as cabras e ovelhas que são mais rústicas e consomem uma gama mais ampla de vegetais e necessitam de menos água. Acontece, em épocas de grande mortalidade nos rebanhos, apenas sobreviverem os efetivos de caprinos, que são assim a última esperança da sobrevivência das pessoas e da reconstituição dos rebanhos. A diversificação do tipo de animais criados e o equilíbrio na composição dos rebanhos constitui, pois, uma estratégia de minimização de riscos, que é adotada por essas comunidades.

O ecossistema em que habitam condiciona drasticamente qualquer outro tipo de atividade econômica ou de produção. A agricultura, muito reduzida, pratica-se durante a estação das chuvas, sempre condicionada à possibilidade de a época de chuva não vir a ser tão abundante que permita o crescimento das culturas até a maturação. Igualmente são utilizadas as margens dos rios secos intermitentes (mulolas), mas mesmo aqui não é frequente a prática do regadio, aproveitando-se mais a umidade existente no subsolo do que a água do leito, quando existe. 
A necessidade da transumância cíclica também dificulta qualquer vocação para a agricultura. Contudo, em certos locais, como nos arredores de Onkokwa e no Erora, no estuário do Rio Kuroka e nos estuários dos outros rios da região, existem lavras de dimensões apreciáveis (por vezes maiores do que um hectare) que estão à mercê de uma melhor época de chuvas, aproveitando a umidade retida no subsolo ou em lagos residuais, e produzem apreciáveis quantidades de produtos agrícolas.

Essas condições determinam que a dispersão dos grupos domésticos tenha em consideração esse aspecto particular da organização econômica. Um pastor, próximo da Espinheira, $33 \mathrm{~km}$ a norte do Yona, informou que se tinha deslocado para esse local com o seu gado, mas que outras pessoas da família se mantinham na onganda, no Erora, onde possuía uma lavra. Cultiva-se milho e massango para alimentação e massambala para o fabrico de cerveja tradicional (makao), além de certos legumes, abóboras, feijão, tomate, cebola e também tabaco para consumo próprio e para comercialização.

$\mathrm{Na}$ verdade, aos criadores transumantes, resta-lhes apenas essa possibilidade de subsistência, já que as pradarias e estepes áridas que habitam registram precipitações demasiado escassas e irregulares para manter uma agricultura dependente da chuva. A sedentarização colocaria outros problemas complexos, a começar pela dificuldade de adaptação dos próprios animais. Em certas regiões onde foi tentada, as perdas do armentio atingiram a ordem dos $80 \%$.

\section{Objetivos}

O objetivo central da criação do Observatório da Transumância é obter um retrato detalhado do fenômeno da transumância no sudoeste de Angola. Como enunciado, a criação desse observatório permitirá criar um acervo de dados cujo tratamento promoverá a elaboração de novas propostas de entendimento do fenômeno nos contextos acima caracterizados e delimitados.

Num primeiro esboço de concretização do projeto, prevê-se a consolidação gradual das atividades desse observatório, compreendendo duas fases principais:

- o observatório, afeto ao Centro de Estudos do Deserto - CE.DO, terá necessariamente uma estrutura física, mas irá constituir-se principalmente como um banco de dados, alimentando-se de informações recolhidas no terreno;

- decorrente da investigação, o observatório desenvolverá suas atividades no sentido do estabelecimento de um programa de investigação/ação que deverá conter, na sua matriz, os seguintes elementos:

- identificação de necessidades e expectativas dos diversos atores locais, regionais e locais; 
- identificação dos recursos necessários para o desenvolvimento das atividades;

- delimitação e caracterização do campo e dos focos de recolha de dados e informação;

- identificação e elaboração dos instrumentos de recolha de informação, métodos e periodicidade;

- determinação da metodologia de análise e interpretação dos dados;

- identificação das possibilidades de utilização dos dados e diversificação dos consumidores.

Como referido, o observatório pretende, de forma muito particular, fornecer dados passíveis de contribuir para uma ação local a mais informada possível. Esse tipo de dados permitirá fornecer à administração local as bases para o trabalho de criação e melhoria das condições básicas de sobrevivência para essas populações transumantes, nomeadamente no que respeita o acesso à água, alimentação, assistência médica e medicamentosa. Por outro lado, contribuir para a concepção e estruturação de alternativas de provisão de serviços sociais itinerantes, como escolas, postos de saúde etc. Em um nível mais abrangente, poderá contribuir para uma melhor delimitação e distribuição do trabalho de concessão e exploração de terras para outros tipos de atividades socioeconômicas na região.

\section{Produtos e repercussões}

Em um nível geral, espera-se que os resultados da investigação se revelem no nível da produção de conhecimento e do apoio à governação e à administração. No nível dos atores locais envolvidos na transumância, as repercussões situam-se no fortalecimento da capacidade de participação nas decisões, na preservação e reforço das estruturas e dinâmicas socioculturais locais. Busca-se a criação e fortalecimento da percepção de fatores de identidade transversais a várias comunidades étnicas e outras entidades sociais. Em termos concretos, o observatório irá focar-se na constituição de uma base de dados; na recolha de documentação e compilação; na divulgação dos dados através de plataformas interativas, publicações e apresentações públicas. 